\title{
Perturbation of cytokinin and ethylene-signalling pathways explain the strong rooting phenotype exhibited by Arabidopsis expressing the
} Schizosaccharomyces pombe mitotic inducer, cdc25

\author{
Natasha D Spadafora ${ }^{1,2}$, David Parfitt ${ }^{1}$, Angela Marchbank', Sherong Li', Leonardo Bruno², Rhys Vaughan ${ }^{1}$, \\ Jeroen Nieuwland', Vicky Buchanan-Wollaston ${ }^{3}$, Robert J Herbert ${ }^{4}$, Maria Beatrice Bitonti ${ }^{2}$, John Doonan ${ }^{5}$, \\ Diego Albani ${ }^{6}$, Els Prinsen ${ }^{7}$, Dennis Francis ${ }^{1}$ and Hilary J Rogers ${ }^{1 *}$
}

\begin{abstract}
Background: Entry into mitosis is regulated by cyclin dependent kinases that in turn are phosphoregulated. In most eukaryotes, phosphoregulation is through WEE1 kinase and CDC25 phosphatase. In higher plants a homologous CDC25 gene is unconfirmed and hence the mitotic inducer Schizosaccharomyces pombe (Sp) cdc25 has been used as a tool in transgenic plants to probe cell cycle function. Expression of Spcdc25 in tobacco BY-2 cells accelerates entry into mitosis and depletes cytokinins; in whole plants it stimulates lateral root production. Here we show, for the first time, that alterations to cytokinin and ethylene signaling explain the rooting phenotype elicited by Spcdc25 expression in Arabidopsis.

Results: Expressing Spcdc25 in Arabidopsis results in increased formation of lateral and adventitious roots, a reduction of primary root width and more isodiametric cells in the root apical meristem (RAM) compared with wild type. Furthermore it stimulates root morphogenesis from hypocotyls when cultured on two way grids of increasing auxin and cytokinin concentrations. Microarray analysis of seedling roots expressing Spcdc25 reveals that expression of 167 genes is changed by $>2$-fold. As well as genes related to stress responses and defence, these include 19 genes related to transcriptional regulation and signaling. Amongst these was the up-regulation of genes associated with ethylene synthesis and signaling. Seedlings expressing Spcdc25 produced 2-fold more ethylene than WT and exhibited a significant reduction in hypocotyl length both in darkness or when exposed to $10 \mathrm{ppm}$ ethylene. Furthermore in Spcdc25 expressing plants, the cytokinin receptor AHK3 was downregulated, and endogenous levels of iPA were reduced whereas endogeous IAA concentrations in the roots increased.
\end{abstract}

Conclusions: We suggest that the reduction in root width and change to a more isodiametric cell phenotype in the RAM in Spcdc25 expressing plants is a response to ethylene over-production. The increased rooting phenotype in Spcdc25 expressing plants is due to an increase in the ratio of endogenous auxin to cytokinin that is known to stimulate an increased rate of lateral root production. Overall, our data reveal important cross talk between cell division and plant growth regulators leading to developmental changes.

\footnotetext{
* Correspondence: rogershj@cardiff.ac.uk

${ }^{1}$ School of Biosciences, Cardiff University, Cardiff CF10 3AT, UK

Full list of author information is available at the end of the article
} 


\section{Background}

Proliferative cells are made competent for DNA replication and mitosis at the G1/S and G2/M boundaries. In Arabidopsis, at $\mathrm{G} 2 / \mathrm{M}$, proliferative cells are regulated by Arath;CDKA;1, and by B-type CDKs, one of which, CDKB1;1, has a single peak of activity at G2/M [1]. In fission yeast, at the G2/M transition, Mik1/Wee1 kinases act redundantly to phosphorylate Tyr15 of the CDK thereby inactivating the latter [2]. Conversely Cdc25 dephosphorylates the same residue enabling CDK activity [3]. Although homologues for the fission yeast wee1 have been identified in several plant species [4-6], a full length homologue of $C D C 25$ has only been found in algae [7] while higher plant genomes have a partial CDC25 gene that lacks the regulatory domain $[8,9]$. Although Arath;CDC25 (At5g03455) encodes a protein capable of phosphatase activity in vitro [8], it induces a short cell length in fission yeast [9] and has a subtle effect on root growth [10], its encoded protein can exhibit arsenate reductase activity $[11,12]$. Thus currently, there is insufficient functional evidence to tag Arath; CDC25 as a bona fide CDC25 cell cycle gene. However, in Nicotiana plumbaginifolia cell cultures a cdc25-like phosphatase activity was detected at the G2/M transition [13] although the identity of the gene involved remains unknown.

In the absence of a clear plant CDC25 homologue, Schizosaccharomyces pombe Spcdc25 expression in plant cells has been useful as a tool to investigate the effects of dephosphorylation of the CDKs on cell division and plant development. Spcdc25 has clear effects on development and on the cell cycle when expressed in tobacco. In $N$. plumbaginifolia it dephosphorylated native CDK and induced cells to enter mitosis [14]. It also induced a small cell size in tobacco plants [15], in tobacco root cultures [16] and in tobacco BY-2 cells [17]. In BY-2 cells, the smaller mitotic cell size induced by $S p c d c 25$ expression was linked to CDKB but not CDKA activity, and a short G2 phase [17]. Furthermore, in cultured primary roots of tobacco, induced $S p c d c 25$ expression caused an increase in the frequency of smaller lateral root primordia, and smaller roots comprising smaller mitotic cells compared with un-induced roots [16].

Expression of $S p c d c 25$ in tobacco cell cultures suggested a link to cytokinin signalling. In plants, cytokinins are required for the $\mathrm{G} 2 / \mathrm{M}$ transition $[18,19]$ and treating tobacco BY-2 cells with lovastatin, an inhibitor of cytokinin biosynthesis, not only suppressed a peak of cytokinin synthesis but also blocked the G2/M transition [18]. However expression of $S p c d c 25$ in tobacco BY-2 cells could over-ride this requirement $[14,17]$ suggesting that the additional phosphatase activity was replacing the cytokinin signal. Furthermore, all moieties of cytokinin were barely above detectable levels in Spcdc25 expressing cells [17]. In tobacco plants expressing Spcdc25, induction of both vegetative and floral shoot morphogenesis from callus suggests that the $S p c d c 25$ expression was mimicking an altered balance of plant growth regulators towards cytokinins; Spcdc25 could replace exogenous cytokinin to induce shoots in culture [20,21]. However, to date, evidence of alterations to endogenous cytokinins that could strengthen the cell cycle link of $S p c d c 25$ to developmental changes is lacking in whole plants.

A two-hybrid screen revealed that Spcdc25 interacts with numerous Arabidopsis proteins including 14-3-3 proteins [22], however to date there is no information on changes in endogenous gene expression as a result of the expression of $S p c d c 25$ in plants. A major aim of the work presented here was to test the relationship between $S p c d c 25$ expression and endogenous cytokinins and to analyse global gene expression in Arabidopsis plants expressing $S p c d c 25$, in which we have also made a detailed phenotypic analysis.

Results presented here extend substantially our previous work in showing that ectopic expression of the mitotic inducer, $S p c d c 25$, results in profound changes to root morphology, meristem architecture and the regulation of the plane of cell division. We further show that in planta Spcdc25 expression (1) depletes endogenous levels of the cytokinin, iPA, (2) down regulates the cytokinin receptor, $A H K 3$, (3) results in over production of auxin and ethylene, (4) up-regulates ethylene biosynthetic genes and (5) induces hypersensitive hypocotyl growth responses to ethylene. Hence perturbation of genes associated with cytokinin and ethylene signalling explain the phenotypes upon expression of this fission yeast mitotic inducer gene. This indicates an important cross-talk between cell cycle regulation at G2/M transition, plant growth regulators and plant morphogenesis.

\section{Results}

Expression of $S p c d c 25$ increases the frequency of lateral roots and adventitious roots but not primary root elongation in Arabidopsis seedlings

Given the root developmental changes induced by Spcdc25 in tobacco, we tested whether Spcdc25 could similarly affect Arabidopsis. Two independent transgenic lines expressing the $B T X:: S p c d c 25$ construct, verified by RT-PCR (shown in Additional file 1), showed a significant increase in the number of lateral roots and lateral root primordia per unit length of primary root, compared with WT in $10 \mathrm{~d}$ old seedlings but no difference in primary root length. (Figure $1 \mathrm{~A}$ and $1 \mathrm{~B}$ ). Hence, the rate of lateral root production per $\mathrm{mm}$ of primary root was substantially higher (1.6-fold) in the Spcdc25 lines compared with WT (Figure 1). 
(A)

\section{BTX::Spcdc25}

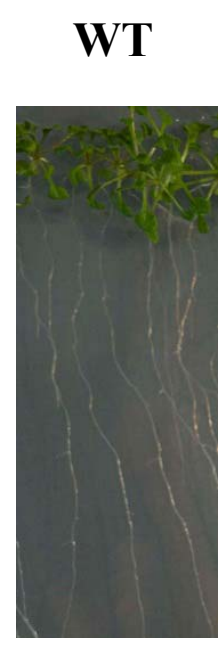

\section{\#9}

\#10
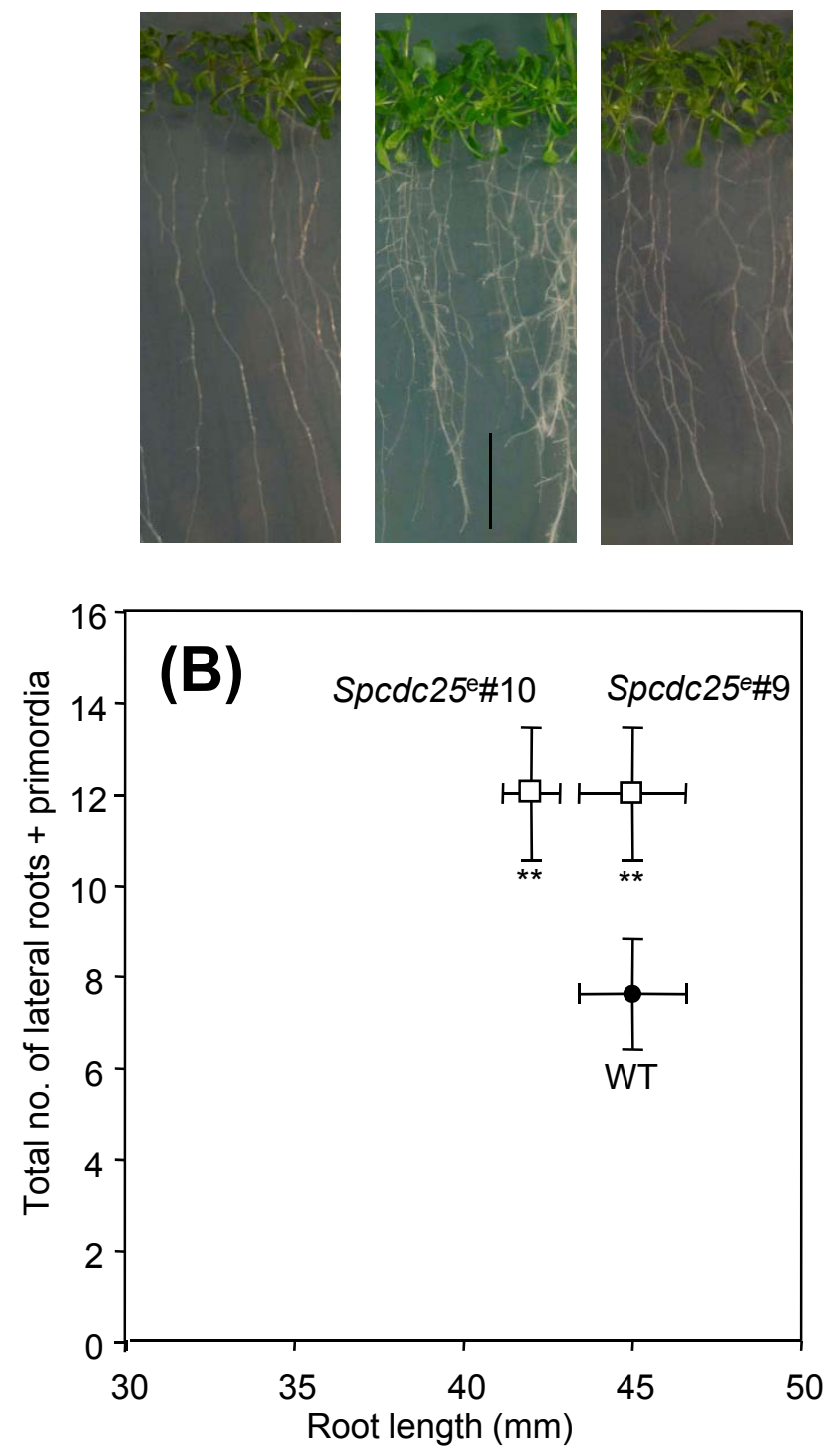

(C)

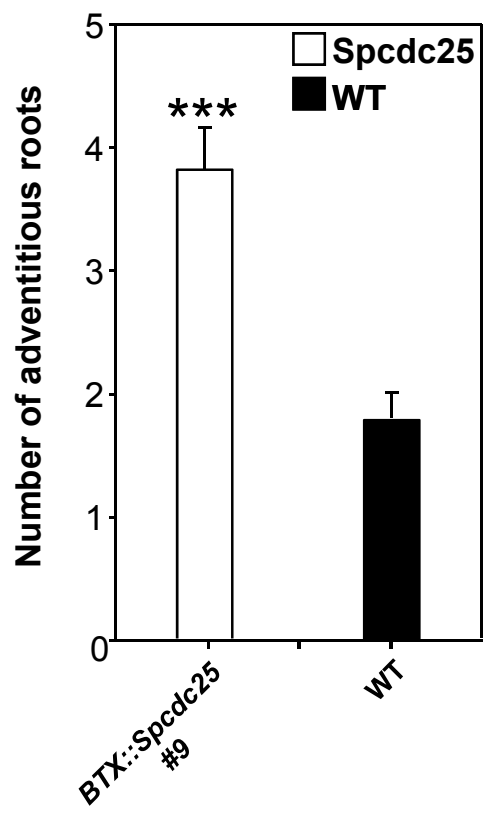

Figure 1 Spcdc25 expression stimulates lateral root growth. (A) Phenotypes of 10 day-old Arabidopsis seedlings: Wild type (WT), and BTX:: Spcdc25 (lines 9 and 10). Bar scale $=10 \mathrm{~mm}$. (B) The relationship between mean total number of lateral roots + lateral root primordia $( \pm$ SE) and mean primary root length $\left(\mathrm{mm} \pm \mathrm{SE}\right.$ ) for 10 day old seedlings grown at $21^{\circ} \mathrm{C}$ : Wild type $(\mathrm{WT})$, and two Spcdc25 expressing lines, 9 and 10 . Root length in Spcdc25 lines 9 and 10 was not significantly different from WT $(P>0.05)$. Number of laterals + primordia were significantly different from WT ( $\left.p={ }^{* *} 0.02\right)$ in Spcdc25 lines 9 and 10 cf WT. The rate of lateral root formation $\mathrm{mm}$ primary root ${ }^{-1}$ for each genotype: $W T=0.17$, Spcdc25 line $10=0.28$, Spcdc25 line $9=0.26$. (C) Adventitious root phenotypes in WT and BTX::Spcdc25 line 9, in $24 \mathrm{~d}$ old seedlings. All data are means $\pm S E$; levels of significance $(P)$ are indicated by Student's $t$-test: $P * * * 00.001, P^{* *} 0.02-0.001 P^{*} 0.02-0.05 ; n=25$ 
We also tested whether expression of Spcdc25 affected the formation of adventitious roots from cultured hypocotyls derived from intact $24 \mathrm{~d}$ old plants and found that Spcdc25 explants produced significantly more than WT (Figure 1C).

\section{Expression of Spcdc25 decreases root meristem width through narrowing of cortical and stelar cell width} A hall-mark feature of $S p c d c 25$ expression in tobacco plants is a small cell size phenotype and we examined whether this was also so in Arabidopsis. We extended this analysis in Arabidopsis to examine RAM architecture in relation to the similar rate of primary root elongation of Spcdc25 compared with WT. Spcdc25 expression affected neither cell length nor cell width for epidermal lineages of the RAM. Indeed, Spcdc25 expression also had little effect on cell length in either the cortex or stele (Figure 2). However, there was a highly significant decrease in cell width for cells of the cortex and stele in Spcdc25 compared with WT (Figure 2). Given little change in cell length between genotypes, the transition point was at comparable distances from the root tip for each tissue (e.g. epidermis in Figure 2). However, consistent with the narrowing of cell width in the cortex and stele, the overall girth of the RAM was narrower $(\mathrm{P}<0.01)$ in Spcdc25 $(91.67 \pm 1.90 \mu \mathrm{m})$ compared with WT $(124 \pm 3.70 \mu \mathrm{m})$ (Figure 2).

At the cellular level, the data suggest that in the cortex and stele, Spcdc25 expression reduces the span of periclinal divisions that in turn would create narrower cell lineages. We tested this hypothesis using confocal microscopy. Here we show that Spcdc25 expression does indeed result in narrower "Körper clusters" compared with wild type (Figure 3 and see Discussion). The net result is a narrower RAM and a narrower primary root system compared with WT. However, clearly, Spcdc25 expression has no effect on anticlinal divisions in the epidermis. The null effect of $S p c d c 25$ on meristematic cell length is consistent with no significant difference in meristem length between genotypes (data not shown) and similar rates of primary root elongation between genotypes (Figure 1). Consistent with this is that in cortical tissue adjacent to young lateral root primordia, mean cortical cell lengths of $75 \pm 10.1$ and $56.86 \pm 10.3$ $\mu \mathrm{m}$ for WT and $S p c d c 25$, respectively were not significantly different $(\mathrm{n}=25$, see Additional file 2$)$.

\section{Expression of $S p c d c 25$ increases rooting from cultured hypocotyls}

In tobacco cell cultures expression of $S p c d c 25$ enables cells to bypass a requirement for cytokinins at the G2/ $\mathrm{M}$ transition; indeed in this line cytokinin levels were depleted [17]. The strong lateral root phenotype in vivo also suggested that auxin levels might be involved in the plant's response to $S p c d c 25$ expression. To explore further this cross-talk between plant growth regulators and the cell cycle, we tested whether application of exogenous cytokinin and auxin might affect rooting in cultured hypocotyls.

In initial experiments we used the grid system of Inoue et al. [23] comprising exposure of explanted hypocotyls to combinations of naphthyl acetic acid (NAA) and Kinetin (Kin) ranging from 25 to $300 \mathrm{ng} \mathrm{ml}^{-}$ ${ }^{1}$ (shown in Additional file 3). From here on we refer to these treatments as NAA/Kin, each prefixed by the appropriate concentration $\left(\mathrm{ng} \mathrm{ml}^{-1}\right)$.

At higher levels of NAA/Kin (e.g. $\geq 200$ NAA) callus and root/shoot formation appeared similar in $S p c d c 25$ and WT, however at 100 NAA, root/shoot formation appeared enhanced in WT compared with $S p c d c 25$. Conversely at $\leq 50$ NAA, root formation appeared enhanced in $S p c d c 25$ compared with WT (NAA/Kin: $50 / 25,50 / 200,25 / 100,25 / 200$ ). Hence, there was the suggestion, that below an auxin threshold ( $\leq 50 \mathrm{NAA})$, hypocotyls from Spcdc25 plants explanted to culture media have increased competence for root formation.

To verify these indicative results we undertook a more rigorous quantitative analysis of this trend by employing four specific NAA/Kin combinations in which we established 25 hypocotyls per treatment (Figure 4). We chose 25NAA/25Kin and 300NAA/300Kin, the minimum and maximum concentrations used in the grids. We further chose 50NAA/200Kin as a combination that induced a stronger rooting response in Spcdc25 compared with WT in the original grids and the converse, 200NAA/ $50 \mathrm{Kin}$. At all of the NAA/Kin combinations tested except the highest, there were significantly more roots produced by the transgenic line expressing Spcdc25 compared to WT (Figure 4A) whereas shoot production was significantly higher only at the two lower auxin concentrations (Figure 4B). Callus formation was only significantly greater in the $S p c d c 25$ expressing line at the lowest auxin and cytokinin concentrations tested (Figure $4 \mathrm{C})$.

\section{Expression of Spcdc25 in Arabidopsis affects expression of 167 genes including genes related to ethylene signalling}

To understand more fully how the expression of Spcdc25 caused clear phenotypic changes in Arabidopsis roots we examined the extent to which the expression of this gene caused alterations in global gene expression occurring in the transformed seedlings. Microarray analysis of Arabidopsis seedling roots expressing $S p c d c 25$ compared to WT revealed that 87 genes were up-regulated $>2$-fold and 80 were down-regulated by $>2$-fold when analysed using Genespring software (see Additional file 4 for the full list of genes). Expression of 


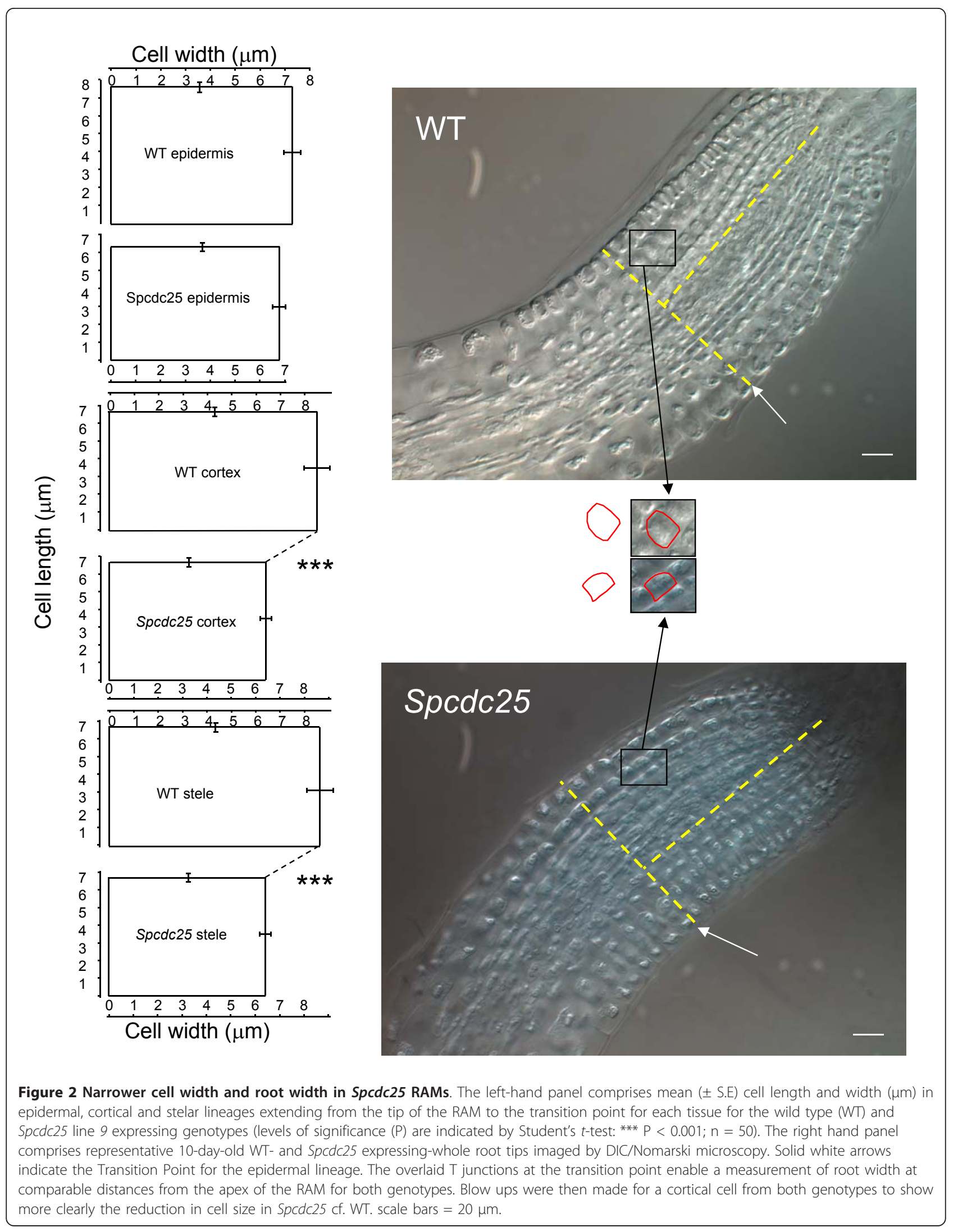




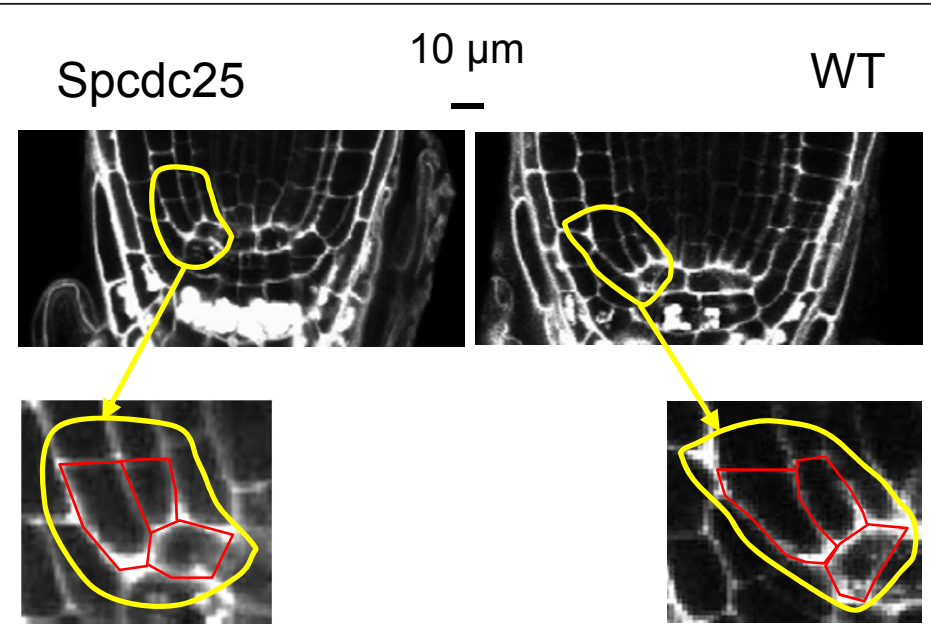

Figure 3 Spcdc25 RAM has narrower cells in Körper $\perp$ divisions compared with wild type. Median confocal images of promeristems of Spcdc25 and WT, each with a tracing around a Körper division immediately adjacent to the quiescent centre, and a subsequent "blow up" of this cluster of cells. Bar scale $=10 \mu \mathrm{m}$.

selected genes was confirmed by real time RT-PCR, (see Additional file 5 for the real-time PCR data).

Of particular interest were 20 differentially expressed genes related to signalling, transcription and plant growth regulators (Table 1), 10 of which were up-regulated while 10 were down regulated in the Spcdc25 line. Three of the differentially expressed genes are related to ethylene signalling. The first (At5g61590), which is a member of a subfamily B-3 of the ethylene responsive $E R F / A P 2$ transcription factors, is up-regulated in $S p c d c 25$ seedlings by 2.6 -fold. The other two genes are down regulated by 2.0 -fold and 5.0-fold respectively: At2g27050, which is a member of the EIN3 family, positive regulators of ethylene responses and At2g25490, known as EBF1, an F-box protein involved in the ubiquitin/proteasome-dependent proteolysis of EIN3, and is thus a negative regulator of ethylene signalling [24]. In addition ACC OXIDASE (At1g12010) expression was up-regulated on the microarrays by 2.6 -fold.

Spcdc25 expression results in changes linked to ethylene metabolism and signalling

The microarray results provided novel information about genes associated with ethylene metabolism in the Spcdc25 plants. Expression levels of the ethylene related genes ERF2/AP2 family member (At5g61590), ACC OXIDASE (At1g12010) and EBF1 (At2g25490) were therefore verified using real time RT-PCR. Expression of both ERF2/AP2 and ACC OXIDASE were up-regulated by at least 1.5 -fold in agreement with the array data. The down-regulation of EBF1 on the array, however was not confirmed (Figure 5A). These data are consistent with increased ethylene production and signalling in Spcdc25 plants.
Given the development of isodiametric cells in the cortex and stele of RAMs in Spcdc25 expressing plants, which is a typical ethylene induced response [25], we tested for further evidence of ethylene-related phenotypes in the Spcdc25 plants. Hypocotyl length was highly significantly reduced $(\mathrm{P}<0.001)$ in 3,4 and 7 day old seedlings of Spcdc 25 plants compared with WT grown in continuous darkness (Figure $5 \mathrm{~B}$ ). This differential effect was nullified when the seedlings were grown in a $16 \mathrm{~h} \mathrm{~L} / 8 \mathrm{~h} \mathrm{D}$ regime. Exposing these genotypes to exogenous ethylene also resulted in a differential magnitude of hypocotyl shortening. In WT, hypocotyl length was not significantly different in the 0 and $10 \mathrm{ppm}$ ethylene treatments but there was a highly significant difference at 100 compared with 0 ppm (Figure 5C). In contrast, in Spcdc25 hypocotyl length was significantly shorter in the $10 \mathrm{ppm}$ treatment compared with $0 \mathrm{ppm}$ but there was no additional shortening at $100 \mathrm{ppm}$ although compared with $0 \mathrm{ppm}$, hypocotyl length was significantly shorter (Figure $5 \mathrm{C}$ ). These data suggest a hypersensitive response of hypocotyls of Spcdc25 plants compared with WT when exposed to 10 ppm ethylene. Moreover, Spcdc25 plants produced 2fold more ethylene than WT (Figure 5D).

\section{Spcdc25 expression in Arabidopsis perturbs the} expression of a cytokinin receptor gene and perturbs endogenous cytokinin and IAA levels

Notable in the microarrays, was the down-regulation of AHK3 in Spcdc25 plants by 2.5 -fold; this gene encodes a putative cytokinin receptor. This result was confirmed by real-time RT-PCR (Figure $5 \mathrm{~A}$ ). We then tested whether endogenous cytokinin levels mirrored $A H K 3$ expression, in roots of Spcdc25 and WT. Data presented 


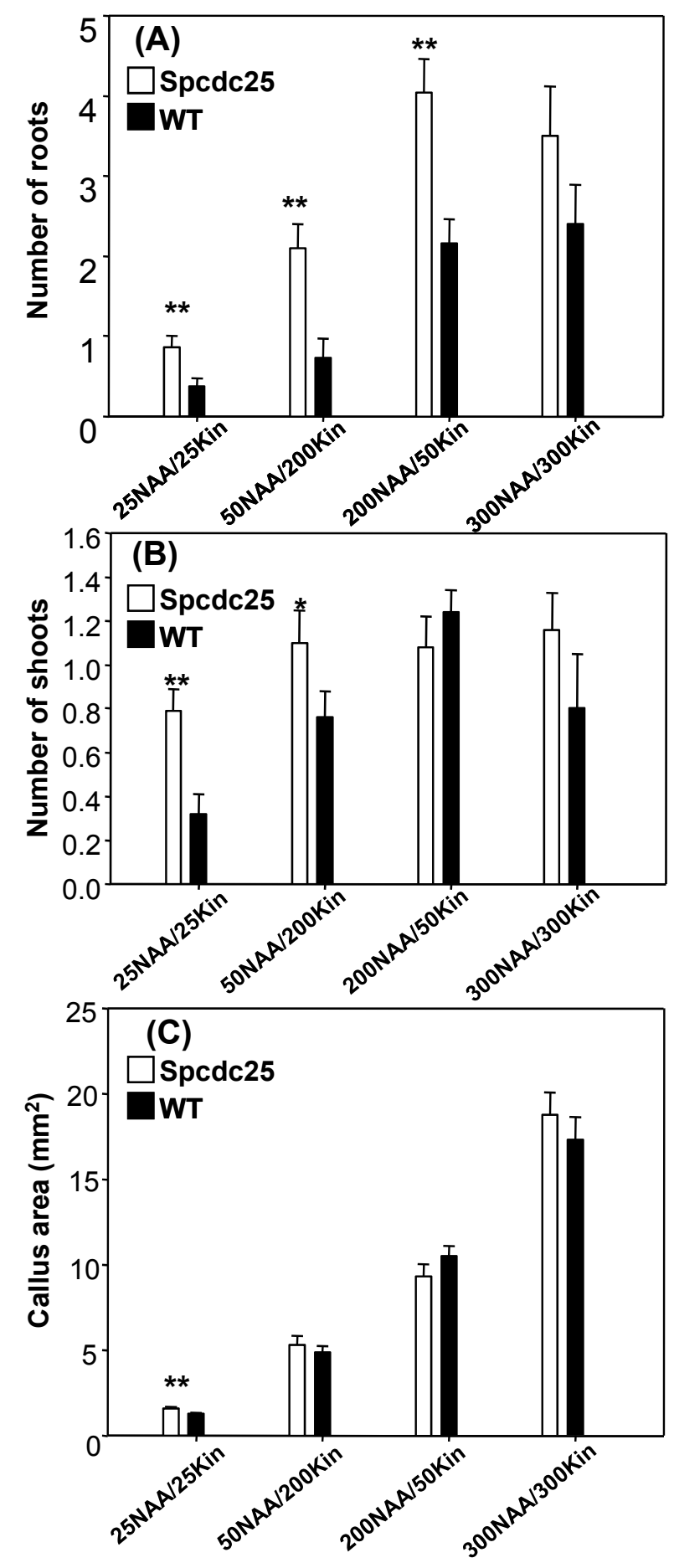

Figure 4 Spcdc25 induces stronger rooting response at $\leq$ 50NAA. Mean ( \pm S.E.) number of (A) roots (B) shoots and (C) callus area in cultures of 14 day old hypocotyls from Spcdc25 expressing line 9 (open bars), and wild type (solid bars) cultured on MS medium supplied with a range of concentrations of kinetin (Kin $\mathrm{ng} \mathrm{ml}^{-1}$ ) and naphthyl acetic acid (NAA ng ml${ }^{-1}$ ) for $30 \mathrm{~d}$. Significance levels are $P$ values from Student t-tests between the transgenic line and WT: ${ }^{*} 0.05-0.02,{ }^{* *} 0.02-0.001 . n=25$ 
Table 1 genes with putative functions in transcriptional regulation or signalling whose expression changed by $>2$ fold in roots of Arabidopsis seedlings expressing Spcdc25 compared to WT

\begin{tabular}{|c|c|c|c|}
\hline $\begin{array}{l}\text { Ratio Spcdc25/ } \\
\text { WT }\end{array}$ & t-test P-value & ATG code & Putative function \\
\hline 2.6 & 0.009 & At5g61590 & member of the ERF (ethylene response factor) subfamily B-3 of ERF/AP2 transcription factor family \\
\hline 2.6 & 0.002 & At1g12010 & 1-aminocyclopropane-1-carboxylate oxidase putative/acc oxidase putative \\
\hline 2.3 & 0.001 & At5g59780 & regulation of transcription, response to ethylene gibberellin, jasmonic acid, and salicylic acid stimuli \\
\hline 2.2 & 0.001 & At5g20030 & RNA binding protein \\
\hline 2.1 & 0.019 & At5g54930 & AT hook motif-containing protein; functions in: DNA binding \\
\hline 2.1 & 0.036 & At1g48260 & SNF1-related kinase (SnRK) member of the CBL-interacting protein kinases (CIPK17). \\
\hline 2.1 & 0.045 & At5g53450 & OBP3-responsive gene 1 (ORG1); functions in: protein kinase activity, kinase activity, \\
\hline 2.0 & 0.040 & At1g69220 & serine/threonine kinase (SIK1) similar to yeast gene PAK1 involved in cytokinesis, actin polarization. \\
\hline 2.0 & 0.042 & At1g08320 & bZIP family transcription factor \\
\hline 2.0 & 0.004 & At3g56970 & OBP3-RESPONSIVE GENE 2, member of the basic helix-loop-helix transcription factor family \\
\hline 0.2 & 0.000 & At2g25490 & Negative regulation of ethylene signalling F-box protein involved in the proteolysis of EIN3 \\
\hline 0.3 & 0.002 & At5g42020 & Luminal binding protein (BiP2) involved proliferation of endosperm nuclei, response to stress \\
\hline 0.3 & 0.029 & At5g14580 & polyribonucleotide nucleotidyltransferase, involved in RNA processing, stability \\
\hline 0.4 & 0.034 & At4g24190 & SHD: ER-resident HSP90-like protein and is involved in regulation of meristem size and organization \\
\hline 0.4 & 0.020 & At1g27320 & AHK3: histidine kinase, a cytokinin receptor. \\
\hline 0.5 & 0.001 & At1g20823 & zinc finger (C3HC4-type RING finger) family protein, response to chitin, a plant-defense elicitor. \\
\hline 0.5 & 0.031 & At2g27050 & transcription factor, ethylene-insensitive3-like1 (EIL1), response to ethylene stimulus \\
\hline 0.5 & 0.044 & At2g02170 & remorin family protein; functions in: DNA binding, high expression in SAM \\
\hline 0.5 & 0.009 & At1g49760 & polyadenylate-binding protein, putative/PABP, putative, similar to poly(A)-binding protein, \\
\hline 0.5 & 0.019 & At2g01150 & RING-H2 finger protein ubiquitin-protein ligase activity \\
\hline
\end{tabular}

in Figure 5E for roots of Spcdc25 plants compared to WT show a 4.8 -fold increase in zeatin riboside (ZR) concentration, zeatin $(\mathrm{Z})$ was unaltered whereas isopentenyladenosine (iPA) was reduced by almost 2-fold (Figure $5 \mathrm{E}$ ). Hence, the cytokinin depletion effect we had observed in tobacco cells in culture was matched regarding iPA in root systems of Arabidopsis. These changes in cytokinins may help to explain the enhanced lateral root phenotype in Spcdc25 plants. Additionally, we detected a substantial (2-fold) increase in free IAA in Spcdc25 roots (Figure 5F), again consistent with the enhanced root branching response.

\section{Discussion}

\section{Spcdc25 expression promotes lateral and adventitious} root production

In tobacco plants, expression of $S p c d c 25$ resulted in a decrease in mitotic cell size and an increase in lateral root production [16]. Results here confirm this effect in Arabidopsis but show that whilst primary root elongation is not promoted by Spcdc25 expression, lateral and adventitious root production most certainly is.

Although in vivo responses are not always mirrored in vitro we further showed this strong rooting phenotype in vitro through culture of hypocotyls in two way combinations of auxin and cytokinin. Noticeably, at the lower end of the auxin concentration range $(\leq 50 \mathrm{mM}$ NAA) but seemingly regardless of exogenous kinetin levels, explanted hypocotyls from Spcdc25 plants were more adept at making roots in vitro. Thus hypocotyls showed greater competence for rooting in vivo and in vitro confirming cross talk between this mitotic inducer gene and development. Indeed, we propose that the increased frequency of lateral roots is a cell cycle effect in the pericycle, based on published evidence that Spcdc25 dephosphorylates native plant CDK [14] and induces both premature CDKB activity and premature mitosis [17].

\section{Spcdc25 expression depletes iPA and raises IAA}

One way in which lateral root production can be enhanced is by cytokinin depletion through over-expression of CYTOKININ OXIDASE [26]. Spcdc25 expression also depletes cytokinin levels in cultured BY-2 cells [17] and led us to hypothesise that a similar $S p c d c 25$-induced reduction in cytokinin levels in Arabidopsis roots might explain the root phenotypes we observe. Cytokinin levels in these plants partly support this hypothesis in that iPA is significantly depleted but neither zeatin nor zeatin riboside are reduced. However, in plants expressing Spcdc25, the cytokinin receptor gene, $A H K 3$ showed reduced expression. Note that there is not a universal 

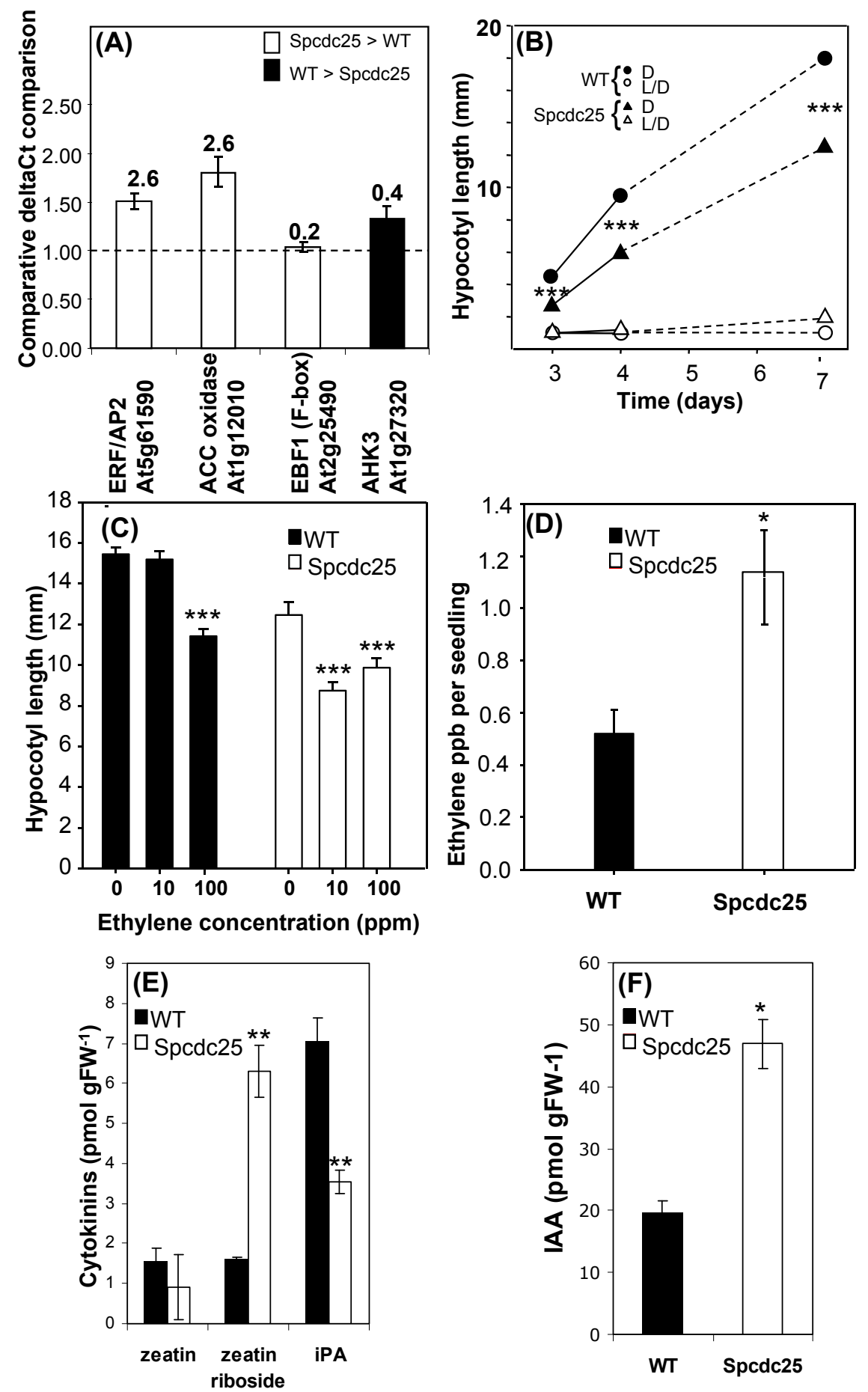

Figure 5 Spcdc25 alters ethylene, cytokinin and auxin synthesis, expression of ethylene and cytokinin signalling genes and hypoctyl growth responses. (A) real time PCR analysis of relative expression of four genes related to ethylene and cytokinin signalling in roots of 10 day old seedlings. $n=3$. (Above each histogram bar is the array result Spcdc25/WT); (B) relationship between hypocotyl length (mm) and time (days), in seedlings grown in dark ( $D$, closed symbols) or $16 \mathrm{~h} \mathrm{~L}, 8 \mathrm{~h} \mathrm{D}(\mathrm{L} / \mathrm{D}$, open symbols), (error bars < diameter of symbols) $\mathrm{n}=25$; (C) hypocotyl length in seedlings exposed to 0,10 or 100 ppm ethylene for 10 days. $n=20$; (D) endogenous ethylene levels (ppb per seedling) in 10 day old seedlings in WT and Spcdc25 $n=3$; number of seedlings measured in each replicate sample, WT 1. 273, 2. 238, 3. 413 ; Spcdc25 1. 181, 2. 276, 3. 188. (E) endogenous cytokinins and (F) endogenous IAA, in whole root systems of 10 day old seedlings. $n=3$. C-F: WT (black bars), Spcdc25 (white bars). All data are means \pm S.E levels of significance $(P)$ are indicated by Student's $t$-test: $P * * * 0.001, P * * 0.02-0.001 P^{*}$ 0.02-0.05 
positive relationship between cytokinin depletion and root branching. For example, Arabidopsis ahk2 ahk3 double mutants had increased zeatin and zeatin riboside levels, in combination with decreased iPA but increased primary root growth as well as more lateral roots [27]. Thus the data presented here, showing a reduction in AHK3 expression with a depletion of iPA level in combination with an increase in trans-zeatin riboside is also consistent with an increase in lateral root production in the $S p c d c 25$ expressing plants. Riefler et al., [27] argue for a feedback mechanism between receptor levels and cytokinin biosynthesis. An increase in mitotic entry by Spcdc25 expression might be feeding back both to cytokinin levels and also to receptor levels with more emphasis on depletion of iPA than other cytokinin moieties.

The steady state level of endogenous cytokinins in plant tissues is a reflection of cytokinin biosynthesis, degradation and transport. Nucleoside-type cytokinins have been proposed as the major transport form [28-31]; iP ribosides and ribotides are transported basipetally together with sucrose via the phloem whereas tZR is transported acropetally via the transpiration stream in the xylem. Moreover, different import carriers are involved in cell-cell transport of free bases and cytokinin nucleosides (for a recent review [32]). The observed reduction in iPA, might indicate an impaired phloem derived transport of iPA towards the roots upon expression of Spcdc25. Hence, our current data highlight subtle cross talk between Spcdc25 expression and cytokinin supply.

Lateral root primordia start in pericycle cells opposite protoxylem poles. When secondary root founder cells are activated, cycling is started again in cells previously held in G2 [33,34]. This is under control of a complex interplay of auxin and cytokinins at the level of biosynthesis and transport. Spcdc25 replaces the normal cytokinin requirement in the CDK dephosphorylation during G2-M resulting in an active CDK in order to unblock the substrate and ATP-binding sites [14]. Notably, in animal cells, cytokinins act as a competitive inhibitor for ATP binding on CDC2 (iP, tZ, cZ), CDK5 (iP, $\mathrm{tZ}, \mathrm{cZ}$ ) and CDK4 (iP is exclusive inhibitor). Although CDK4 has no orthologue in planta, it is clear that iP is an exclusive cytokinin in the control of the G1/S transition in animal cells [35]. Hence, the reduction in iPA concentration in the root reported here may be important in cell cycle control in clusters of pericyle cells that serve as secondary root founders.

Another strong feature of enhanced root branching in Arabidopsis is positive regulation by IAA as demonstrated through both genetic and physiological manipulations $[33,36,37]$. Thus, the greater the amount of IAA relative to cytokinins in primary roots, the greater the frequency of lateral roots. Notably, we also detected an increased amount of IAA in roots of Spcdc25 compared with WT, which again is consistent with the strong rooting phenotype reported here.

\section{Spcdc25 expression alters root architecture}

$S p c d c 25$ had a null effect on primary root elongation yet its expression altered the architecture of the meristem and the overall width of the root. Notably, cells in the cortex and stele were smaller but more isodiametric in Spcdc25 compared with wild type, caused by a reduction in cell width but not cell length. Körper type " $\perp$ " divisions occur in apical initials of RAMs whereby a periclinal division creates two files of cells that then form lineages as a result of repeated transverse divisions [38]. Hence, the periclinal division of apical initials has a profound effect on the overall width of the RAM. Here we hypothesise that premature entry into mitosis, activated by $S p c d c 25$ expression, restricts the width of these periclinal divisions in both cortex and stele with the net result being a narrower RAM and a narrower primary root system compared with WT. Spcdc25 can indeed alter the plane of cell divisions to induce isodiametric growth of BY-2 cells and other tobacco lines in culture $[17,39]$. Note that in cultured tobacco cells, transverse divisions are the norm and that isodiametric cells come about through an increased frequency of longitudinal (periclinal) divisions. This type of effect is also suggested to result in an increased frequency of periclinal divisions in the pericycle producing the strong lateral root phenotype in both tobacco [15] and here in Arabidopsis.

\section{Spcdc25 expression perturbs ethylene signalling}

An induction of isodiametric cell growth is a classic ethylene response [25] and the hypersensitive hypocotyl shortening response reported here either in the presence or absence of exogenous ethylene and its overproduction in Spcdc25 plants all point to an ethylene effect at the cellular level. To our knowledge, an ethylene induced isodiametric cell phenotype in RAMs has not been overtly reported in the published literature although in a study of ethylene effects on the quiescent centre of Arabidopsis, images of WT RAMs treated with ACC were narrower than untreated controls (Figure 3A, $B$ and $3 E$ of [40]). Nevertheless, the up-regulation of ethylene associated genes, hypocotyl length suppression in darkness see also, [41] and isodiametric RAM cellular phenotype tend to suggest that changes in ethylene synthesis or signalling in Spcdc25 plants are regulating these effects. Previous work established that exogenous ethylene has no substantial effect on rates of cell division in RAMs of either pea or corn [42] nor did we detect any difference in primary root elongation rates in 
Spcdc25 compared with WT. However, in Arabidopsis ethylene does modulate cell division in the quiescent centre [40] and through interactions with auxin assists in the regulation of root cap size [43].

\section{Conclusions}

In conclusion, we demonstrate that ectopic expression of the mitotic inducer gene, Spcdc25 in Arabidopsis has several important but explainable consequences. At a developmental level, $S p c d c 25$ expression depletes iPA levels, down regulates $A H K 3$ expression but raises IAA levels and promotes lateral root production. This alteration in the endogenous auxin-cyokinin milieu is entirely consistent with the stimulation of lateral roots. At a cellular level, Spcdc25 perturbs ethylene signalling, induces the plants to over produce ethylene that in turn probably alters planes of cell division that lead to isodiametric cell growth in RAMs. We have shown previously that $S p c d c 25$ expression causes premature mitosis at a reduced cell size through shortening of the G2 phase of the cell cycle and bypasses a requirement for cytokinins at the G2/M transition [17]. Hence our data are important in highlighting cross talk between cell cycle control, hormonal signalling and development (Figure 6).

\section{Methods}

Transformation of Arabidopsis and plant growth

The Spcdc25 construct, BTX::Spcdc25, comprising the Spcdc25 ORF driven by an attenuated 35S CaMV promoter as described in [17], was used to transform Arabidopsis thaliana $c v$. Columbia plants by the floral dip method [44]. Expression of the transgene was checked in several independent transformant lines by RT-PCR using primers specific for the transgene P7 5'TTAGGTCCCCTTCTCCGATG and P101 5'- TCAATGAGTCCTCCCTTCACG). Two lines were selected for their expression profile (BTX::Spcdc25 line 9 and line 10). Initial experiments showed that the phenotype of the two lines was very similar and hence further experiments were performed only with line 9 . From here on, the genotypes used in this study are referred to as WT (wild type) or Spcdc25 (BTX::Spcdc25 expressing) plants.

For root measurements, seeds were surface sterilised and sown aseptically $1.5 \mathrm{~cm}$ apart onto Murashige and Skoog (MS) medium [45] agar in $90 \mathrm{~mm}$ diameter Petridishes. Seedlings were stratified at $6^{\circ} \mathrm{C}$ for $24 \mathrm{~h}$ and grown vertically at $21^{\circ} \mathrm{C}$ with $16 \mathrm{~h}$ light (fluence rate $=$ $300 \mu \mathrm{m} \mathrm{m}^{-2} \mathrm{~s}^{-1}$ ) $8 \mathrm{~h}$ darkness in a Sanyo-Gallenkamp Arabidopsis chamber. To score lateral root primordia,

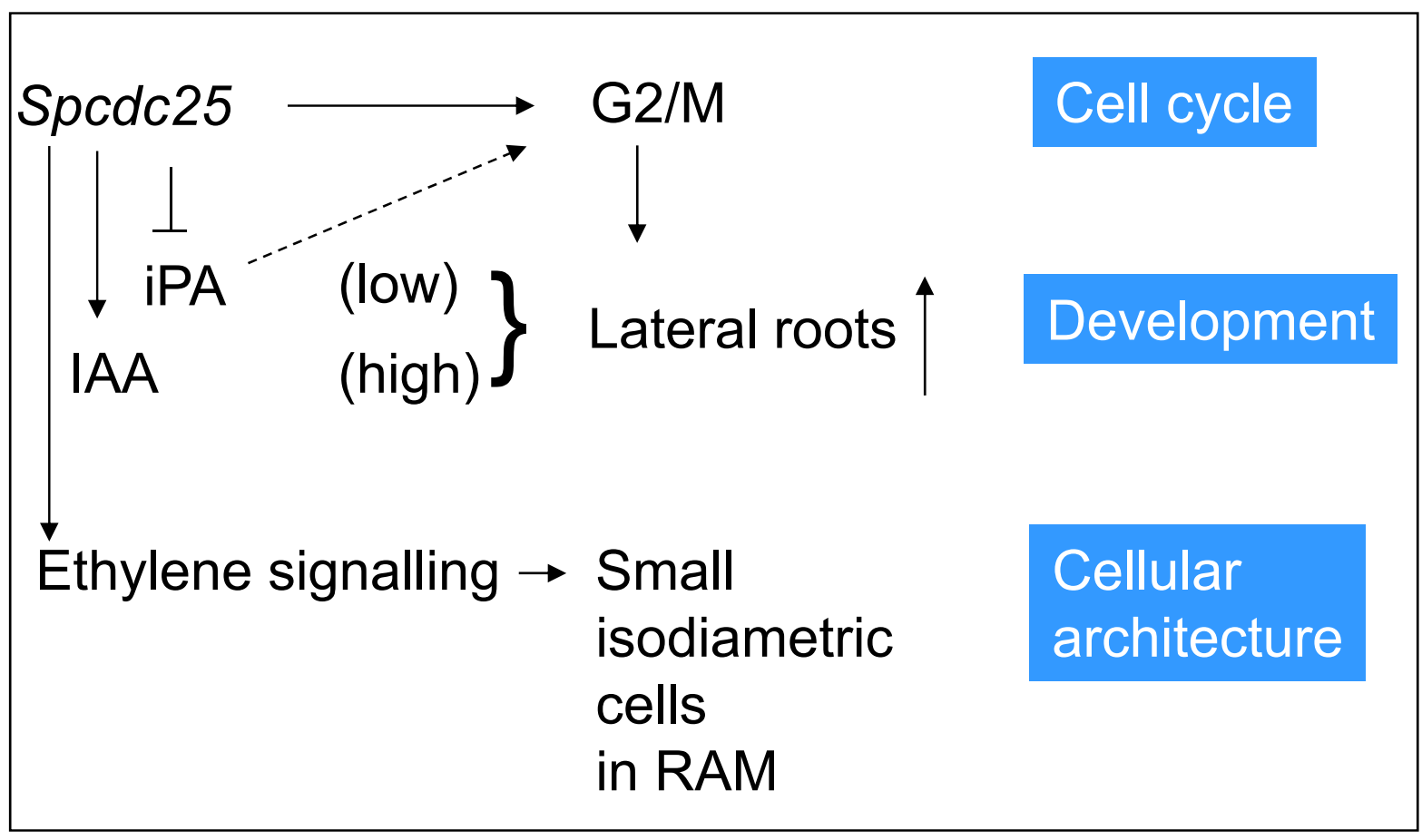

Figure 6 Cross talk between Spcdc25, hormonal signalling and development. Spcdc25 depletes and replaces cytokinins at the G2/M transition of cell cycle (Orchard et al., 2005), depletes iPA and raises IAA to promote lateral root formation and stimulates ethylene signalling to promote small isodiametric cells in cortex and stele of primary roots (data reported here) 
seedlings were fixed in 3 to 1 absolute ethanol to glacial acetic acid and Feulgen stained [46]. Primary root length, numbers of lateral roots and lateral root primordia were recorded using a stereo dissecting microscope (Nikon Z100). Additionally, hypocotyls were dissected from 24 day old seedlings and the number of adventitious roots were scored.

\section{Analysis of root apical meristem phenotypes}

Ten day old seedlings grown as above were used for the RAM analyses. Roots were fixed and mounted on slides in 8:3:1 chloral hydrate:distilled water: glycerol taking care to apply a coverslip gently [47]. Cell length, width and number were measured in three tissues of the RAM: epidermis, cortex and stele using a ZeissAxiophot set for D.I.C. interfaced to Image analysis software (PixiLINK (C) Capture S.E.). Measurements were taken along longitudinal cell files of epidermis, cortex and mid-stele until the parameter spanned a cell that suddenly increased its cell length/width substantially compared with the previous one. For all genotypes, and for all tissues, this was between a 1.40- to 1.95 -fold increase. This was the transition point beyond which those cells began to elongate substantially and is taken to be the basipetal border of the promeristem for each tissue. The cellular measurements were undertaken at either x 20 or $\mathrm{x} 40$. Images of whole root tips were captured using a low power, x10 objective.

For confocal images, roots were prepared as described in [48] and visualised using a Leica TCS SP2 (Spectral Confocal and Multiphoton System) confocal scanning laser microscope interfaced to ImageJ software (ImageJ64).

\section{RNA extraction and real time RT-PCR}

RNA extractions from roots of Spcdc25 and WT seedlings, grown as described above, were performed using 2 $\mathrm{ml}$ TRI reagent (SIGMA-ALDRICH, Dorset, UK) according to the manufacturer's protocol, following grinding to a powder in liquid nitrogen using a mortar and pestle. RNA was treated with RQ1 Dnase (PROMEGA, Southampton, UK) to remove residual genomic DNA. cDNA was synthesised as described in [49].

Seedling root cDNA (30 ng) was amplified in qRTPCR reactions in a $20 \mu \mathrm{l}$ total volume containing: $10 \mu \mathrm{l}$ $2 \times$ PowerSYBR Green PCR Master Mix (Applied Biosystems); $400 \mathrm{nM}$ of each primer; $30 \mathrm{ng}$ cDNA. Reactions were performed in triplicate with the following cycles: $95^{\circ} \mathrm{C}$ for $10 \mathrm{~min}, 40$ cycles of $95^{\circ} \mathrm{C}$ for $15 \mathrm{~s}$ and $60^{\circ} \mathrm{C}$ for $1 \mathrm{~min}$. To test primer specificity, melting curve analysis (from $60^{\circ} \mathrm{C}$ to $95^{\circ} \mathrm{C}$ with an increasing heat rate of $0.5^{\circ} \mathrm{C}$ $\mathrm{s}^{-1}$ ) was performed after amplifications.

Relative quantification of gene expression data was carried out with the $2^{\text {-DDCT }}$ or comparative CT method [50].
Expression levels were normalized with the CT values obtained for the housekeeping gene UBQ10 (At4G05320F, 5'- CACACTCCACTTGGTCTTGCGT-3'; At4G05320R, 5'- TGGTCTTTCCGGTGAGAGTCTTCA-3'; [51]. The primers used for qRT-PCR of target genes ERF/AP2 (At5g61590), ACC oxidase (At1g12010), EBF1 (At2g25490) and $A H K 3$ (At1g27320) are listed in Additional file 6.

\section{Microarray analysis}

Messenger RNA was amplified from purified total RNA using the MessageAmp aRNA kit (AMBION, Huntingdon, Cambs, UK) according to the manufacturer's protocol from $5 \mu \mathrm{g}$ extracted total RNA. The CyScribe PostLabelling Kit (AMERSHAM BIOSCIENCES, Little Chalfont, Bucks. UK) was used to label $1 \mu \mathrm{g}$ aRNA, with either $\mathrm{Cy} 3$ or $\mathrm{Cy} 5$ according to the manufacturers' instructions, using $1 \mu \mathrm{g}$ of aRNA. Each labelled RNA pair was freeze-dried and resuspended in $50 \mu \mathrm{l}$ of hybridisation buffer containing $25 \%$ formamide, $5 \times$ SSC, $0.1 \%$ SDS, $0.5 \mathrm{mg} / \mathrm{ml}$ poly $(\mathrm{dA}), 0.5 \mathrm{mg} / \mathrm{ml}$ yeast tRNA. CATMA v 3 arrays comprising 24000 gene probes ([52]; http://www.catma.org) were hybridised with the labelled RNA which was heated to $95^{\circ} \mathrm{C}$ for $5 \mathrm{~min}$ and applied to the microarray slide surface. A second microarray slide was lowered over the labelled RNA and the slides were hybridised back-to-back overnight in a humid chamber at $42^{\circ} \mathrm{C}$. Four slides were used for hybridisations including a dye swap for each probe pair. Following hybridisation, the slides were washed and scanned using an Affymetrix 428 array scanner with the supplied software (AFFYMETRIX, Santa Clara, CA, USA) at $532 \mathrm{~nm}$ (Cy3) and $633 \mathrm{~nm}$ (Cy5). Scanned images were quantified using Imagene version 5 software (BIODISCOVERY, El Segundo, CA, USA). Spot quality labelling (flags) was defined for empty spots with a signal strength threshold of 1 , and for shape regularity with a threshold of 0.4 . The median signal intensity across each spot and the median background intensity were calculated in both channels, and these data were exported into GeneSpring version 6 (AGILENT, Santa Clara, CA, USA). Background intensity was subtracted from spot intensity for both channels giving the background-corrected spot intensity.

Data analysis was carried out using the GeneSpring microarray data analysis package. Ratios between mutant and wild type expression were calculated and levels for the four replicates were averaged. Genes showing an average ratio above 2 or below 0.5 were selected and, following a Benjamini and Hochberg false discovery rate test (BHFDR), genes with $\mathrm{P}$ value $>0.05$ were excluded.

\section{Hypocotyl and ethylene measurements}

WT and Spcdc25 seeds were surface sterilised and stratified as above and seedlings grown in either continuous 
dark or $16 \mathrm{~h} \mathrm{~L} / 8 \mathrm{~h} \mathrm{D}$ at $21^{\circ} \mathrm{C}$. Hypocotyl length was recorded at 3, 4 and 7 days following germination. Effects of exogenous ethylene were measured by sealing plates with Nescofilm and injecting 0,10 or $100 \mathrm{ppm}$ ethylene through a predrilled, sealed hole in the lid of the Petri dish. Hypocotyl measurements were then made as above. To measure endogenous ethylene, $0.015 \mathrm{~g}$ seeds of WT or Spcdc25 were sown onto the surface of $5 \mathrm{ml} 1 \times$ MS in $10 \mathrm{ml}$ glass head space vials (Chromacol, Thermo Scientific, Loughborough, UK), seeds were stratified at $4^{\circ} \mathrm{C}$ for $24 \mathrm{~h}$ then grown at $21^{\circ} \mathrm{C}$ for 10 days in the dark. Headspace concentration of ethylene was measured on a Clarus 500, modified model 2101 analyzer (PerkinElmer, MA, USA), retention time was confirmed using pure ethylene and quantification was calibrated using a standard gas mixture (Scott Specialty Gases, mixture 54).

\section{Cytokinin and IAA measurements}

Frozen samples were ground in liquid nitrogen and transferred to Bieleski [53] solvent $(10 \mathrm{ml} / \mathrm{g}$ fresh weight). Deuterated standards (100 pmol $\left[{ }^{13} \mathrm{C}_{6}\right.$-phenyl]IAA (Cambridge Isotope Laboratory Inc., Andover, MA, USA) and $10 \mathrm{pmol}$ each for cytokinins $\left(\left[{ }^{2} \mathrm{H}_{5}\right] \mathrm{DHZ},\left[{ }^{2} \mathrm{H}_{5}\right]\right.$ [9R]DHZ, $\left[{ }^{2} \mathrm{H}_{5}\right](9 \mathrm{G})$ DHZ, $\left[{ }^{2} \mathrm{H}_{6}\right] \mathrm{iP},\left[{ }^{2} \mathrm{H}_{6}\right][9 \mathrm{R}] \mathrm{iP},\left[{ }^{2} \mathrm{H}_{6}\right](9$ G)iP, $\left[{ }^{2} \mathrm{H}_{5}\right](7 \mathrm{G}) \mathrm{DHZ},\left[{ }^{2} \mathrm{H}_{5}\right](\mathrm{OG}) \mathrm{DHZ},\left[{ }^{2} \mathrm{H}_{5}\right](\mathrm{OG})[9 \mathrm{R}]$ DHZ, $\left.\left[{ }^{2} \mathrm{H}_{6}\right](7 \mathrm{G}) \mathrm{iP}\right)$, OlchemIm Inc. Olomouc, Czech Rep) were added to the extracts and incubated overnight at $-20^{\circ} \mathrm{C}$. Cytokinins were purified by solid phase extraction combining DEAE-Sephadex (HG Healthcare, Uppsala Sweden) and RP-C18 (500 mg, Varian, Middelburg, The Netherlands) cartridges. Purified extracts were loaded onto immunoaffinity columns containing monoclonal antibodies against isoprenoid cytokinins (OlchemIm). Cytokinins were analysed by UPLC-TQD (ACQUITY TQD mass spectrometer (Waters, Milford, MA, USA) using an ES + interphase (based on $[54,55]$ ). Chromatograms were analysed using Masslynx and Quanlynx v4.1 software (Waters, Milford, MA, USA) and cytokinin concentrations were calculated according to the principles of isotope dilution.

\section{Additional material}

Additional file 1: Expression levels of Spcdc25 in transgenic lines of Arabidopsis. RT-PCR of BTX::Spcdc25 lines 9 and 10 showing expression of the transgene in both lines (lower band is primer dimer).

Additional file 2: Figure S2. Null effect of Spcdc25 expression on cell length in mature regions of primary root. DIC/Nomarski images of regions of primary roots exhibiting young lateral root primordia (YLRP) in WT and Spcdc25. Mean $( \pm$ SE) cortical cell length. $W T=75.14 \pm 10.10$ Spcdc25 $=56.86 \pm 11.61 \mu \mathrm{m} . \mathrm{n}=25$. Bar scale $=40 \mu \mathrm{m}$.

Additional file 3: Expression of Spcdc25 induces increased rooting in cultured hypocotyls at NAA/Kin: 50/100, 50/200, 25/50, 25/200. Hypocotyls of $14 \mathrm{~d}$ old plants of (A) wild type (WT) (B) BTX::Spcdc25 (line 9) cultured on two-way concentration gradients of increasing concentrations ( $\mathrm{ng} \mathrm{m}^{-1}$ ) of naphthyl acetic acid (NAA) and kinetin (Kin) for $30 \mathrm{~d}$; representative grids from 3-6 replicate experiments. Cells boxed indicate the NAA/Kin concentrations used for further analysis. Scale bar = $1 \mathrm{~mm}$.

Additional file 4: Table showing genes up-or down-regulated by 2fold or more (Spcdc25/WT).

Additional file 5: Real time PCR verification of the microarray results. Above each histogram bar (Spcdc25/WT) is the microarray result (Spcdc25/WT). $\mathrm{n}=3$.

Additional file 6: Table of real time PCR Primers.

\section{Abbreviations}

CDK: Cyclin-dependent kinases; Kin: Kinetin; NAA: Naphthyl acetic acid; Tyr15: Tyrosine15.

\section{Acknowledgements}

We thank the BBSRC for funding AM under grant no. P10942. NS thanks the University of Calabria for an international research award (Borsa di Specializzazione all'Estero per Giovani Ricercatori), and Cardiff and the University of Worcester (UW) for a research studentship and the John Innes Centre, UK for additional financial support. Research was also supported by grants from the Research Foundation Flanders (FWO): FWO Research Community (W0.038.04 N) to EP. RJH thanks UW for sabbatical leave to work in Cardiff. DF thanks the University of Sassari for funding sabbatical work in the DA lab. We thank Steve Hope for sequencing, Lyndon Tuck for growth of plants, Xiaohong Tang for assistance with ethylene gas measurements and Se Sevgi Öden and Tim Willems for assistance with hormone measurements.

\section{Author details}

${ }^{1}$ School of Biosciences, Cardiff University, Cardiff CF10 3AT, UK. ${ }^{2}$ Dipartimento di Ecologia, Università della Calabria, Arcavacata di Rende, Cosenza I-87030, Italy. ${ }^{3}$ School of Life Sciences, University of Warwick, Wellesbourne, Warwick CV35 9EF, UK. ${ }^{4}$ Institute of Science and the Environment, University of Worcester, Henwick Grove, Worcester WR2 6AJ, UK. ${ }^{5}$ Plant Phenomics Centre, Institute of Biological, Environmental and Rural Sciences, Penglais, Aberystwyth University, Ceredigion SY23 3DA,

Aberystwyth, UK. ${ }^{6}$ Department of Botanical, Ecological and Geological Sciences, University of Sassari, Via Piandanna 4, Sassari 07100, Italy. ${ }^{7}$ Department of Biology, University of Antwerp, Groenenborgerlaan 171, Antwerp B-2020, Belgium.

\section{Authors' contributions}

Natasha Spadafora undertook expression analyses and real time PCR, root phenotyping, tissue culture grids, confocal microscopy and hypocotyl growth analyses, David Parfitt undertook microarray analyses, Angela Marchbank and Li Sherong created transgenic plants, Leonardo Bruno assisted with real time PCR and confocal microscopy, Rhys Vaughan undertook measurements of ethylene sensitivity and ethylene production; Jeroen Nieuwland assisted with DIC microscopy; Vicky Buchanan-Wollaston assisted with microarray analyses, Robert Herbert assisted with expression analyses and ethylene measurements, Beatrice Bitonti assisted with real time PCR and the writing of the manuscript, John Doonan assisted with expression analyses, Diego Albani assisted with DIC microscopy, Els Prinsen undertook endogenous hormone measurements, Dennis Francis assisted with phenotype analyses, DIC microscopy and drafted the manuscript. Hilary Rogers assisted in expression analyses, ethylene measurements and jointly with DF drafted the final version of the manuscript. All authors contributed at the draft stage of writing and all approved the final manuscript.

Received: 21 October 2011 Accepted: 27 March 2012 Published: 27 March 2012

\section{References}

1. Sorrell DA, Menges M, Healy JMS, Deveaux Y, Amano C, Su Y, Nakagami H, Shinmyo A, Doonan J, Sekine M, Murray JAH: Cell cycle regulation of 
cyclin-dependent kinases in tobacco cultivar Bright Yellow-2 cells. Plant Physiol 2001, 126:1214-1223.

2. Featherstone $C$, Russell P: Fission yeast ${ }_{p} 107^{\text {wee } 1}$ mitotic inhibitor is a tyrosine/serine kinase. Nature 1991, 349:808-811.

3. Russell P, Nurse P: $c d c 25+$ functions as an inducer of mitotic control of fission yeast. Cell 1986, 45:145-153.

4. Sun Y, Dilkes BP, Zhang C, Dante RA, Carneiro NP, Lowe KS, Jug R, GordonKamm WJ, Larkins BA: Characterization of maize (Zea mays L.) Wee1 and its activity in developing endosperm. Proc Natl Acad Sci USA 1999, 96:4180-4185.

5. Sorrell DA, Marchbank A, McMahon K, Dickinson JR, Rogers HJ, Francis D: A WEE1 homologue from Arabidopsis thaliana. Planta 2002, 215:518-522.

6. Gonzalez N, Hernould M, Delmas F, Gevaudant F, Duffe P, Causse M, Mouras A, Chevalier C: Molecular characterization of a WEE1 gene homologue in tomato (Lycopersicon esculentum Mill.). Plant Mol Biol 2004, 56:849-861.

7. Khadaroo B, Robbens S, Ferraz C, Derelle E, Eychenie S, Cooke R, Peaucellier G, Delseny M, Demaille J, Van de Peer Y, et al: The first green lineage cdc25 dual-specificity phosphatase. Cell Cycle 2004, 3:513-518.

8. Landrieu I, da Costa M, De Veylder L, Dewitte F, Vandepoele K, Hassan S, Wieruszeski J-M, Faure J-D, Van Montague M, Inze D, Lippens G: A small CDC25 dual-specificity tyrosine-phosphatase isoform in Arabidopsis thaliana. Proc Nat Acad Sc USA 2004, 101:13380-13385.

9. Sorrell DA, Chrimes D, Dickinson JR, Rogers HJ, Francis D: The Arabidopsis CDC25 induces a short cell length when over expressed in fission yeast: evidence for cell cycle function. New Phytol 2005, 165:425-428.

10. Spadafora ND, Doonan JH, Herbert RJ, Bitonti NB, Wallace E, Rogers HJ, Francis D: Arabidopsis T-DNA insertional lines for $C D C 25$ are hypersensitive to hydroxyurea but not to zeocin or salt stress. Ann Bot 2011, 107:1183-1192

11. Bleeker PM, Hakvoort HWJ, Bliek M, Souer E, Schat H: Enhanced arsenate reduction by a CDC25-like tyrosine phosphatase explains increased phytochelatin accumulation in arsenate-tolerant Holcus lanatus. Plant $J$ 2006, 45:917-929.

12. Dhankher OP, Rosen BP, McKinney EC, Meagher RB: Hyperaccumulation of arsenic in the shoots of Arabidopsis silenced for arsenate reductase(ACR 2). Proc Nat Acad Sci 2006, 103:5413-5418.

13. Zhang K, Letham DS, John PC: Cytokinin controls the cell cycle at mitosis by stimulating the tyrosine dephosphorylation and activation of p34cdc2-like H1 histone kinase. Planta 1996, 200:2-12.

14. Zhang K, Diderich L, John PCL: The cytokinin requirement for cell division in cultured Nicotiana plumbaginofolia cells can be satisfied by yeast Cdc25 tyrosine phosphatase. Implications for mechanisms of cytokinin response and plant development. Plant Physiol 2005, 137:308-316.

15. Bell MH, Halford NG, Ormrod JC, Francis D: Tobacco plants transformed with $\mathrm{cdc} 25$, a mitotic inducer gene from fission yeast. Plant Mol Biol 1993, 23:445-451.

16. McKibbin R, Halford NG, Francis D: Expression of fission yeast $c d c 25$ alters the frequency of lateral root formation in transgenic tobacco. Plant $\mathrm{Mol}$ Biol 1998, 36:601-612.

17. Orchard CB, Siciliano I, Sorrell D, Marchbank A, Rogers HJ, Francis D, Herbert RJ, Suchomelova P, Lipavska H, Azmi A, Van Onckelen H: Tobacco BY-2 cells expressing fission yeast cdc25 bypass a G2/M block on the cell cycle. Plant J 2005, 44:290-299.

18. Redig P, Shaul O, Inze D, Van Montagu M, Van Onckelen H: Levels of endogenous cytokinins, indole-3-acetic acid and abscisic acid during the cell cycle of synchronized tobacco BY-2 cells. FEBS Lett 1996, 391:175-180.

19. Laureys F, Dewitte W, Witters E, Van Montagu M, Inze D, Van Onckelen H: Zeatin is indispensable for the G2-M transition in tobacco BY-2 cells. FEBS Lett 1998, 426:29-32.

20. Suchomelova P, Velgova D, Masek T, Francis D, Rogers HJ, Marchbank AM, Lipavska $\mathrm{H}$ : The fission yeast cell cycle regulator, $c d c 25$, induces de novo shoot formation in tobacco: evidence of a cytokinin-like effect. Plant Physiol Biochem 2004, 42:49-55.

21. Teichmanová M, Mašková $\mathrm{P}$, Vojvodová $\mathrm{P}$, Krekule J, Francis $\mathrm{D}$, Lipavská $\mathrm{H}$ : The fission yeast mitotic activator, $c d c 25$, and sucrose induce early flowering synergistically in the day-neutral Nicotiana tabacum cv. Samsun. New Phytol 2007, 176:804-812.

22. Sorrell DA, Marchbank AM, Chrimes DA, Dickinson JR, Rogers HJ, Francis $D$, Grierson CS, Halford NG: The Arabidopsis 14-3-3 protein, GF14 $\omega$, binds to the Schizosaccharomyces pombe $\mathrm{Cdc} 25$ phosphatase and rescues checkpoint defects in the rad24- mutant. Planta 2003, 218:50-57.

23. Inoue T, Higuchi M, Hashimoto Y, Seki M, Kobayashi M, Kato T, Tabata S, Shinozaki K, Kakimoto T: Identification of CRE1 as a cytokinin receptor from Arabidopsis. Nature 2001, 409:1060-1063.

24. Guo H, Ecker JR: Plant responses to ethylene gas are mediated by SCF (EBF1/EBF2)-dependent proteolysis of EIN3 transcription factor. Cell 2003, 115:667

25. Eisinger W: Regulation of pea internode expansion by ethylene. Ann Rev Plant Physiol 1983, 34:225-240

26. Werner T, Motyka V, Laucou V, Smets R, Van Onckelen H, Schmúlling T: Cytokinin-deficient transgenic Arabidopsis plant show multiple developmental alterations indicating opposite functions of cytokinins in the regulation of shoot and root meristem activity. Plant Cell 2003, 15:2532-2550.

27. Riefler M, Novak O, Strnad M, Schmülling T: Arabidopsis cytokinin receptor mutants reveal functions in shoot growth, leaf senescence, seed Size, germination, root development, and cytokinin metabolism. Plant Cell 2006, 18:40-54.

28. Mok DW, Mok MC: Cytokinin metabolism and action. Ann Rev Plant Physiol Plant Mol Biol 2001, 52:89-118.

29. Hirose N, Makita N, Yamaya T, Sakakibara H: Functional characterization and expression analysis of a gene, OsENT2, encoding an equilibrative nucleoside transporter in rice suggest a function in cytokinin transport. Plant Physiol 2005, 138:196-206.

30. Kudo T, Kiba T, Sakibara H: Metabolism and long-distance translocation of cytokinins. J Integ Plant Biol 2010, 52:53-60.

31. Sun J, Hirose N, Wang X, Wen P, Xue L, Sakakibara H, Zuo J: Arabidopsis SOI33/AtENT8 gene encodes a putative equilibrative nucleoside transporter that is involved in cytokinin transport in planta. J Integ Plant Biol 2005, 47:588-603.

32. Kakimoto T: Perception and signal transduction of cytokinins. Ann Rev Plant Biol 2003, 54:605-627.

33. Malamy JE, Benfey PN: Down and out in Arabidopsis: the formation of lateral roots. Trends Plant Sci 1997, 2:390-396.

34. Rost TL: The organization of roots of dicotyledonous plants and the positions of control points. Ann Bot 2011, 107:1213-1222.

35. Veselý J, Havliček L, Strnad M, Blow JJ, Donella-deana A, Pinna L, Letham DS, Kato J, Detivaud L, Leclerc S, Meijer L: Inhibition of cyclindependent kinases by purine analogues. Eur J Biochem 1994, 224:771-786.

36. Celenza JL, Grisafi PL, Fink GR: A pathway for lateral root formation in Arabidopsis thaliana. Genes Dev 1995, 9:2131-2142.

37. Fukaki H, Okushima Y, Tasaka M: Auxin-mediated lateral root formation in higher plants. Int Rev Cytol 2007, 256:111-137.

38. Schüepp O: Untersuchen über Wachstum und Formwechsel von Vetationspunkten. Jahrbuch Wiss Botanik 1917, 57:17-79.

39. Lipavská H, Mašková P, Vojvodová P: Regulatory dephoshorylation of CDK at G2/M in plants: yeast mitotic phosphatase cdc25 induces cytokininlike effects in transgenic tobacco morphogenesis. Ann Bot 2011, 107:1071-1086.

40. Ortega-Martinez O, Pernas M, Carol RJ, Dolan L: Ethylene modulates stemcell division in the Arabidopsis thaliana root. Science 2007, 317:507-510.

41. Neljubow D: Uber die horizontale Nutation der Stengel von Pisum sativum und einiger anderen Pflanzen. Beihrage und Botanik Zentralblatt 1901, 10:128-139

42. Barlow PW: The effect of ethylene on root meristems of Pisum sativum and Zea mays. Planta 1976, 131:235-243.

43. Ponce G, Barlow PW, Feldman L, Cassab Gl: Auxin and ethylene interactions control mitotic activity of the quiescent centre, root cap size and pattern of cap cell differentiation in maize. Plant Cell Env 2005, 28:719-732.

44. Clough SJ, Bent AJ: Floral dip: a simplified method for Agrobacteriummediated transformation of Arabidopsis thaliana. Plant J 1998, 16:735-743.

45. Murashige T, Skoog F: A revised medium for rapid growth and bioassays with tobacco tissue cultures. Physiol Plant 1962, 15:473-479.

46. Armstrong SW, Francis D: Differences in cell cycle duration of sister cells in secondary root meristems of Cocos nucifera L. Ann Bot 1985, 56:803-814.

47. Perilli S, Sabatini S: Analysis of root meristem size development. In Plant Developmental Biology, Methods in Molecular Biology. Edited by: Henig L, Köhler C. Heidelberg: Springer; 2010:177-187. 
48. Truernit E, Siemering KR, Hodge S, Grbic V, Haseloff J: A map of KNAT gene expression in the Arabidopsis root. Plant Mol Biol 2006, 60:1-20.

49. Parfitt D, Herbert RJ, Rogers HJ, Francis D: Differential expression of putative floral genes in Pharbitis nil shoot apices cultured on glucose compared with sucrose. J Exp Bot 2004, 55:2169-2177.

50. Livak KJ, Schmittgen TD: Analysis of relative gene expression data using real-time quantitative PCR and the 2_DDCT method. Methods 2001, 25:402-408.

51. Czechowski T, Bari RP, Stitt M, Scheible WR, Udvardi MK: Real-time RT-PCR profiling of over 1400 Arabidopsis transcription factors: unprecedented sensitivity reveals novel root- and shoot-specific genes. Plant J 2004, 38:366-379.

52. Allemeersch J, Durinck S, Vanderhaeghen R, Alard P, Maes R, Seeuws $K$, Bogaert T, Coddens K, Deschouwer K, Van Hummelen P, Vuylsteke M, Moreau Y, Kwekkeboom J, Wijfjes AHM, May S, Beynon J, Hilson P, Kuiper MTR: Benchmarking the CATMA microarray: a novel tool for Arabidopsis transcriptome analysis. Plant Physiol 2005, 137:588-601.

53. Bieleski RL: The problem of halting enzyme action when extracting plant tissues. Anal Biochem 1964, 121:431-442.

54. Prinsen E, Van Dongen W, Esmans EL, Van Onckelen H: Micro and Capillary LC-MS/MS: A New Dimension in Phytohormone Research. J Chromatog 1998, 826:25-37.

55. Prinsen E, Van-Laer S, Oden S, Van-Onckelen H: Auxin analysis. In Plant hormone protocols. Edited by: Tucker GA. Totowa: Humana Press; 2000:49-65.

doi:10.1186/1471-2229-12-45

Cite this article as: Spadafora et al.: Perturbation of cytokinin and ethylene-signalling pathways explain the strong rooting phenotype exhibited by Arabidopsis expressing the Schizosaccharomyces pombe mitotic inducer, cdc25. BMC Plant Biology 2012 12:45.

\section{Submit your next manuscript to BioMed Central} and take full advantage of:

- Convenient online submission

- Thorough peer review

- No space constraints or color figure charges

- Immediate publication on acceptance

- Inclusion in PubMed, CAS, Scopus and Google Scholar

- Research which is freely available for redistribution

Submit your manuscript at www.biomedcentral.com/submit
Biomed Central 